\title{
Development of qualitative analytical profile of saffron in poly herbal gel's by hptlc
}

\author{
${ }^{1}$ Safeena Sheikh, ${ }^{2}$ Suhail Asghar, ${ }^{3}$ Showkat Ahmad
}

\begin{abstract}
A qualitative HPTLC method has been developed for the identification of saffron from saffron raw material and a Polyherbal gel's containing saffron in it as one of main component. Chromatographic separation of the drug was performed on aluminum backed plates coated with silica gel $60 F 254$ as the stationary phase and the solvent system consisted of n-butanol: Glacial acetic acid: Water (4:1:2). Densitometric evaluation of the separated zones was performed at 366nm. The drug was satisfactorily resolved with the other plant involved and also with the formulation excipients.
\end{abstract}

Key Words: TLC, densitometry, Polyherbal formulation, gel, Saffron and Saffron gel.

\section{INTRODUCTION:}

Saffron $^{1}$ is considered to be the world's most expensive spice. The flower of crocus sativus is a light purple, but it is the threads like reddish colored stigma of the flower.

The term saffron ("filaments") refers to the dried dark red stigma. The factors which are very important in saffron are crocin (color), picrocrocin (flavor) and safranal (aroma). Higher amount of these compounds in saffron provide higher quality of saffron. Due to its high value, saffron is susceptible to adulteration, usually by adding other plants (Cuscuta plantifloratea. ligules) of calendula officinalis L., stigmata of zea may L. or by adding other parts of the saffron plants itself.

It is used in skin eruptions and poisoning, cures sidhma-a type of leucoderma, head ache, ulcer and jantu-parasitic infection. It is also used to treat impotency in male, uterine tonic and emmenogogue, leucorhhoea, ammenrrhoea and painful labour; abortificient; used to treat cough and asthama, promotes strength, nausea, along with other internal and external uses its extract also acts as an anti tumour ${ }^{2,6}$ agent.

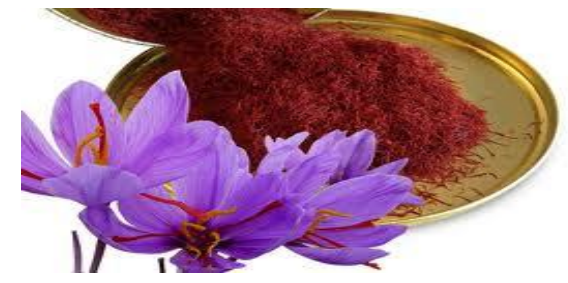

Figure-1: Shows the flowers of saffron (i.e. Crocus sativus) with its beautiful stigma.

The gel contains the saffron and aloe Vera which is an excellent cosmetic aid for keeping the skin radiant and free from blemishes and eruptions. The gel with saffron makes skin glow and rejuvenate. It is a light greaseless formula and suitable for all skin types.

The saffron massage gel is light weight formula which gets absorbed in to skin and aids massage. It instantly unveils a brighter, smoother and even toned skin; very useful for clean up and damp skin which imparts glow to skin. It reveals more translucent and bright complexion with redefined texture after massage.

The kumkumadi lepa ${ }^{2}$ is prescribed in acne and allied skin affections. Kumkumaadyam tailum for promoting complexion (application on hyper pigmented lesions of skin) and for blemishes and freckles. Saffron promotes the complexion. Literature survey reveals that there is no method available which describes the identification of saffron in a polyherbal saffron gel by HPTLC finger printing method. There are many TLC ${ }^{3}$, HPLC $^{7-8}$, HPTLC ${ }^{4}$ and GC $^{5}$ method available for the analysis for bulk drug (Saffron), saffron extract and nanoparticle formulation ${ }^{4}$, and saffron metabolites by HPLC method; but no method available which describes the identification of saffron from the herbal and polyherbal pharmaceutical or cosmeceutical gel formulation, so need for identification is of prime importance. Hence, the objective of this investigation is to develop the simple, reliable and economical procedure for the identification of saffron from bulk and in a cosmeceutical gel formulation by HPTLC. 


\section{Procurement of materials:}

\section{MATERIAL AND METHODS}

Saffron Dried was procured from Ashwini traders Mumbai market, India. A marketed Polyherbal saffron gel was used for the development of qualitative profile for evaluation.

\section{SAMPLE PREPARATIONS:}

\section{Preparation of Reference sample (Saffron RM):}

Weigh accurately saffron RM $10.0 \mathrm{mg}$ in $250 \mathrm{ml}$ conical flask add $50.0 \mathrm{ml}$ methanol and allow it to shake for 30.0minutes on rotary shaker vigorously. Discontinue the shaking cool and filter. Repeat the above said procedure thrice; combine the methanolic filtrate and subjected to evaporation on water bath. Dissolve the remaining dried content in $5 \mathrm{ml}$ of methanol; use this solution for the further analysis.

Preparation of Test sample-1(Saffron gel-1):

Weigh accurately $10.0 \mathrm{~g}$ of the gel formulation in $250 \mathrm{ml}$ conical flask add $50.0 \mathrm{ml}$ of methanol and allow it to shake for 30.0minutes on rotary shaker vigorously. Discontinue the shaking cool and filter. Repeat the above said procedure thrice; combine the methanolic filtrate and subjected to evaporation on water bath. Dissolve the remaining dried content in $5 \mathrm{ml}$ of methanol; use this solution for the further analysis.

Preparation of Test sample-2(Saffron gel-2):

Weigh accurately $10.0 \mathrm{~g}$ of the gel formulation in $250 \mathrm{ml}$ conical flask add $50.0 \mathrm{ml}$ of methanol and allow it to shake for 30.0minutes on rotary shaker vigorously. Discontinue the shaking cool and filter. Repeat the above said procedure thrice; combine the methanolic filtrate and subjected to evaporation on water bath. Dissolve the remaining dried content in $5 \mathrm{ml}$ of methanol; use this solution for the further analysis.

\section{INSTRUMENTATION:}

A Camag HPTLC instrument was used for the complete analysis. The TLC plates were $10 \mathrm{x} 10 \mathrm{~cm}$, Precoated with silica gel $\mathrm{F}_{254}$ TLC plates (E.Merck) (0.2mm thickness); spotting device was Camag Linomat 5 sample applicator, Camag (Muttenz, Switzerland); syringe was a 100 $\mu$ l (Hamilton); developing chamber was a CAMAG glass twin trough chamber (20x 10); densitometer was CAMAG TLC Scanner 3 having winCATS software for execution of instrument.

\section{HPTLC procedure:}

A Camag Linomat HPTLC system equipped with an automatic TLC sampler, TLC scanner, and integrated software was used for the analysis. The separation was carried out by applying the sample solutions as 10,15 , and $20 \mu \mathrm{l}$ of sample solution along with the reference sample on a pre-coated TLC plate silica gel 60 $\mathrm{F}_{254}(10 \mathrm{~cm} \times 10 \mathrm{~cm})$ plate of $0.2 \mathrm{~mm}$ layer thickness. Chromatographic development was carried in n-Butanol: Glacial acetic Acid: Water $(4: 1: 2 \mathrm{v} / \mathrm{v} / \mathrm{v})$ as mobile phase. The samples were applied on the plate as $6 \mathrm{~mm}$ wide bands with a semiautomatic TLC sampler under flow of inert gas, application speed 150n1/sec. The length of development distance was fixed at $80.0 \mathrm{~mm}$ from the base of the TLC plate. After that TLC plates were dried in a current of air, followed by heating on Camag HPTLC plate heater III at $60^{\circ} \mathrm{C}$ for about 5 mintues. The scanning was carried out at $366 \mathrm{~nm}$. The identity of the separated bands of saffron in the sample track was confirmed by overlying their UV absorption spectra with those of the respective bands of reference sample using a Camag TLC Scanner 3 with win CATS software. The spectral scanning was performed over the range of 200 to $700 \mathrm{~nm}$. The sources of radiations utilized were tungsten and deuterium.

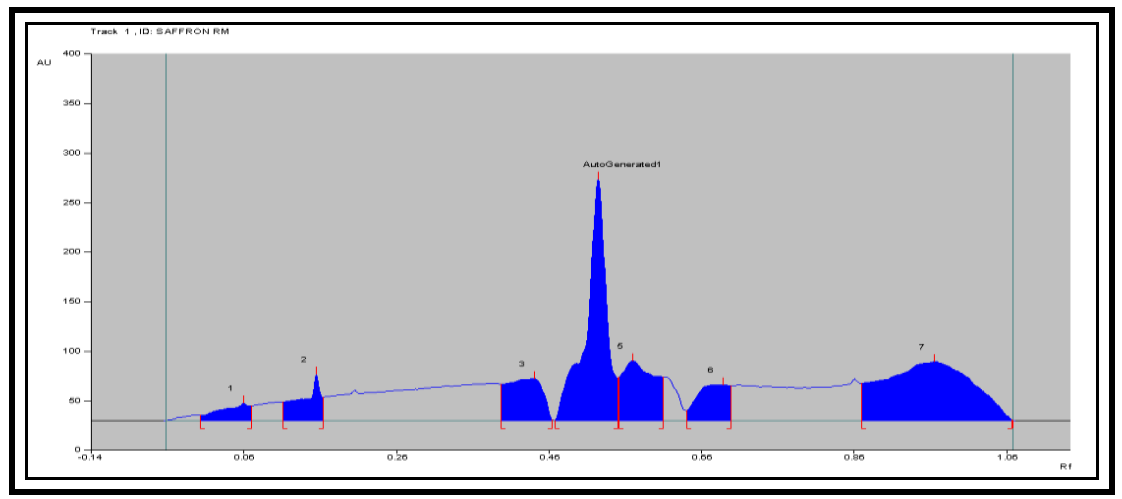

Figure-2: Shows HPTLC finger printing profile of Saffron raw material. 


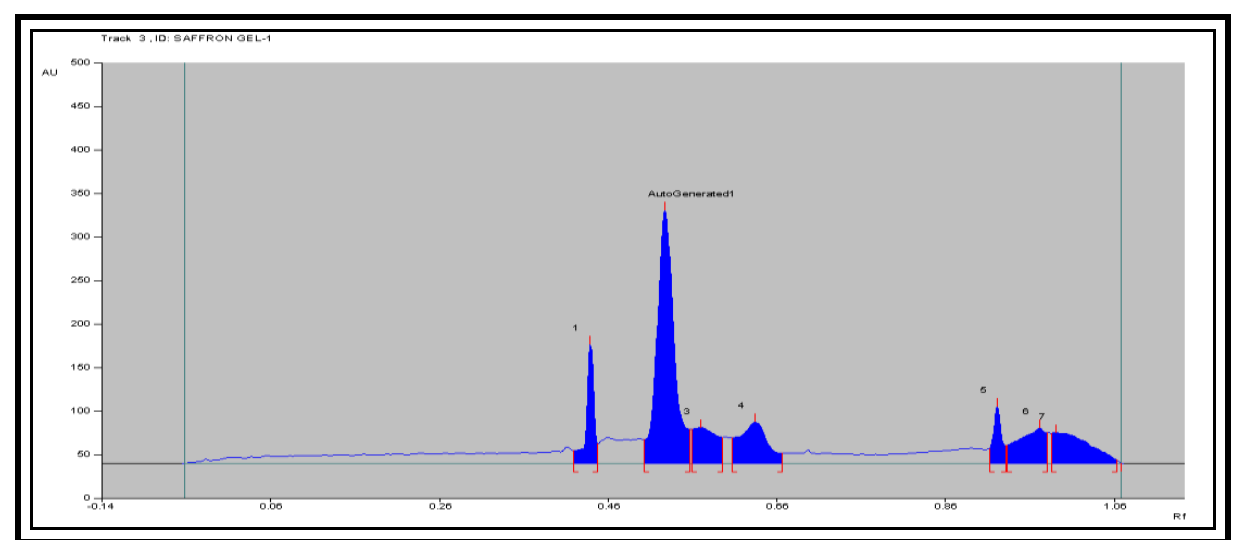

Figure-3: Shows HPTLC finger printing profile of saffron gel-1.

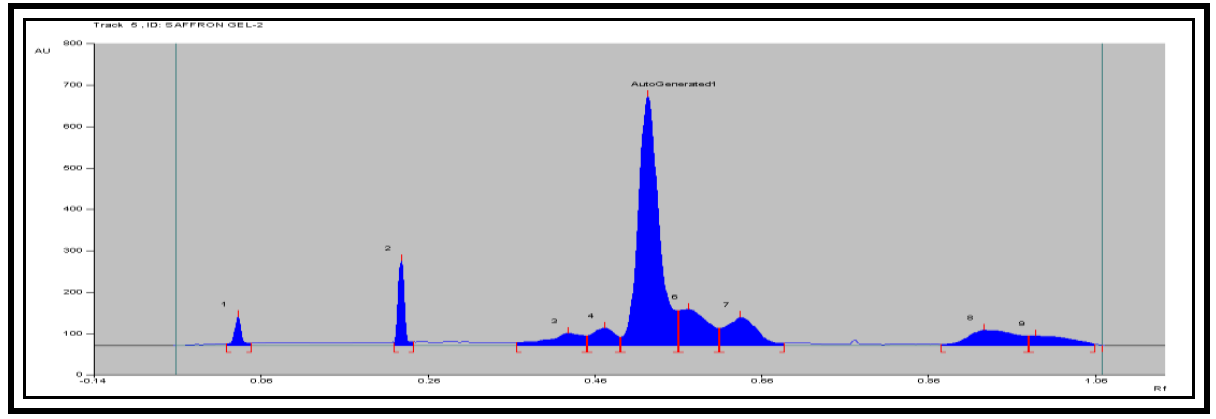

Figure-4: Shows HPTLC finger printing profile of saffron gel-2.

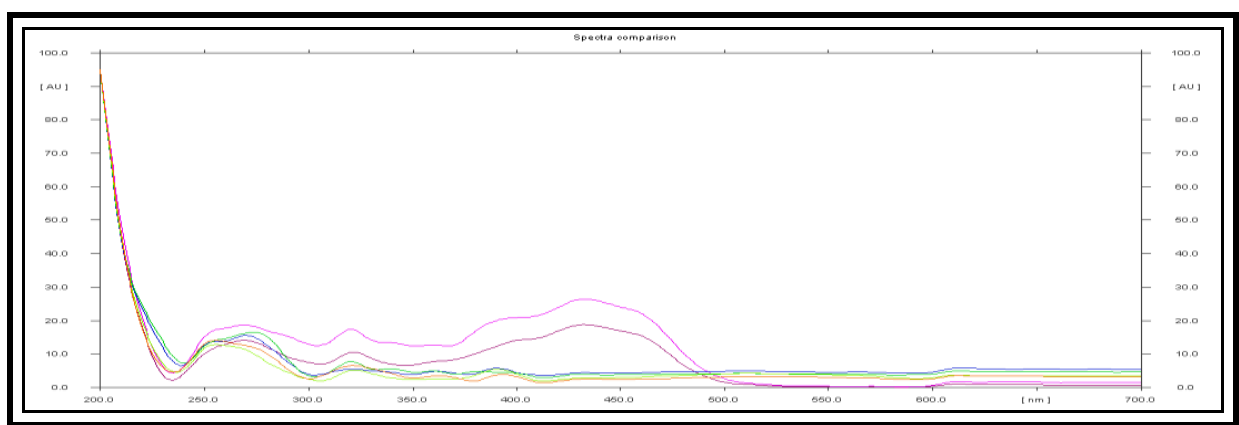

Figure-5: Overlay spectra of assigning peak (as autogenerated-1 in figure-1,2 and 3) from all the tracks shows that the selected spot/peak are of similar chemical nature which confirms the presence of saffron in the poly herbal gel formulations.

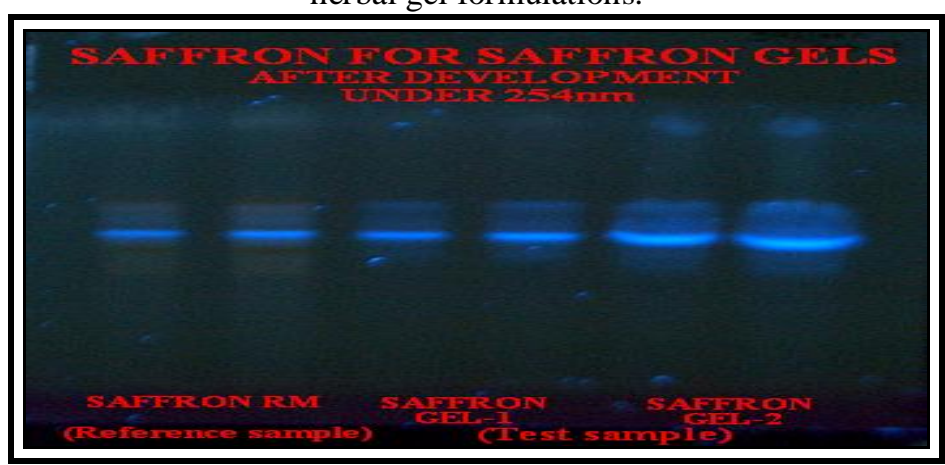

Figure-6: Shows Chromatogram of saffron and saffron gel under 366nm after development. Qualitative estimation: 
Chromatographic profile of saffron and saffron gel by HPTLC method is shown in table 1 .

Table 1: Chromatographic profile of crude drug of crocus sativus (Saffron RM) and their gel formulations.

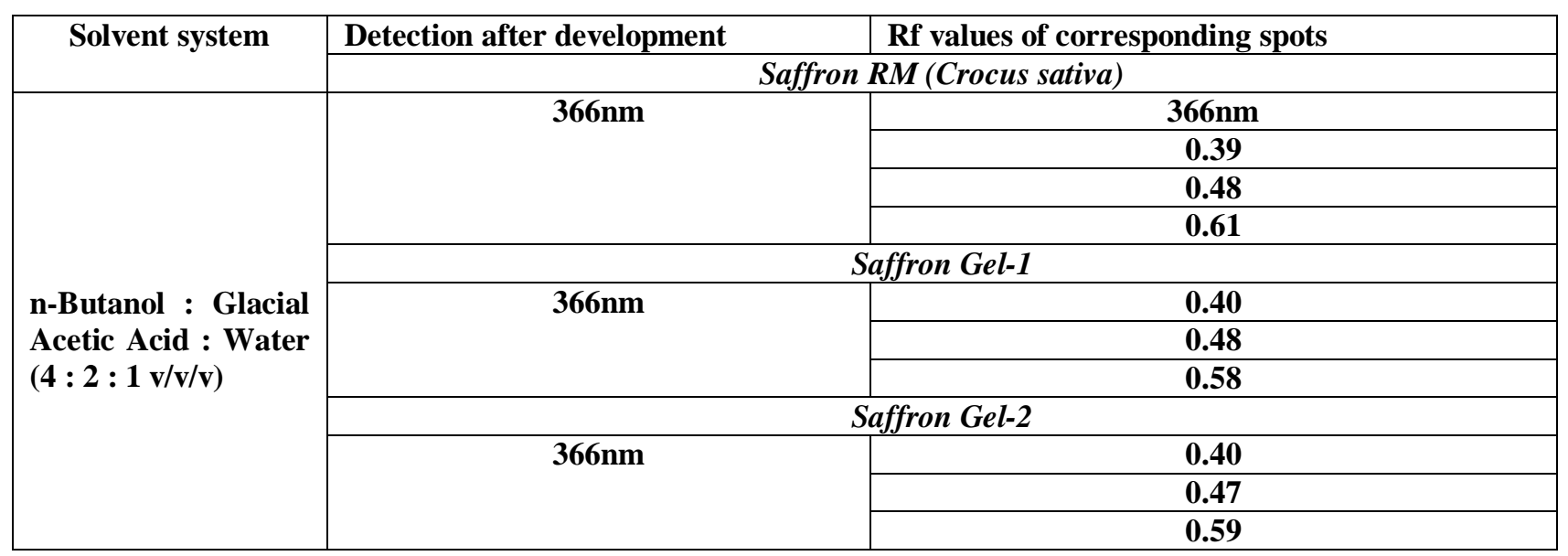

The simple accurate, specific and precise HPTLC method was developed for saffron identification from gel base formulations. The developed qualitative finger printing profile of saffron and polyherbal gels (i.e. saffron gel-1 and saffron gel-2) shows well separated and resolved bands (Figure: 7). The Rf values under $366 \mathrm{~nm}$ and day light confirms the corresponding spots (Table 1).

\section{RESULT AND DISCUSSION:}

Figure 2 shows the densitometric finger printing profile of saffron raw material while figure 3 and 4 shows the densitometric finger printing profile of saffron gel-1 and saffron gel-2 respectively after scanning under $366 \mathrm{~nm}$. The overlain spectra (Figure 5) confirms that the assigning peak was of same herb and of same chemical nature. Figure 6 shows the chromatogram under 366nm.

\section{CONCLUSIONS:}

A simple, rapid, less expensive, reliable HPTLC method has developed for the analysis of saffron as bulk drug and in pharmaceutical polyherbal gel formulations without any interference from excipients. The data shows that the method is suitable for routine quality control analysis of the drugs and drug formulations.

\section{REFERENCES:}

[1.] Gupta D. P, “The Herbs”, 2008, Edition-I, page no. 164-165.

[2.] "Anti tumour compounds of saffron extract indicated that crocin was responsible for the anti tumour activity" International journal of pharmacognosy, vol 32 (2), 105-114

[3.] Wagner H, S.Baldt" plant drug analysis a thin layer chromatographic atlas march-1996, Edition-II, page no. $282-288$.

[4.] Quantitative analysis of safranal in saffron extract and nanoparticle formulation by a validated high-performance thin-layer chromatographic method Shadab Ahmad Pathan' Sanjar Alam Gaurav K. Jain , Syed M. A. Zaidi, Sohail Akhter, Divya Vohora, Roop K. Khar, Farhan J. Ahmad., Article first published online: 27 OCT 2009.,DOI: 10.1002/pca.118.

[5.] Analysis of saffron volatile fraction by TD-GC-MS and e-nose, Manuel Carmona, Javier Martínez, Amaya Zalacain, Ma Luz Rodríguez-Méndez, José Antonio de Saja, Gonzalo Luis Alonso.

[6.] Chemical analysis and antitumor activity of natural and semi-natural carotenoids of saffron. P.A. Tarantilis, M.G. Polissiou.

[7.] Methods for the analysis of the saffron metabolites crocin, crocetins, picrocrocin and safranal for the determination of the quality of the spice using thin-layer chromatography, high-performance liquid chromatography and gas chromatography. , V. Sujata, G.A. Ravishankar, L.V. Venkataraman., Autotrophic Cell Culture Discipline, Central Food Technological Research Institute, Mysore570013 India.

[8.] HPLC quantification of major active components from 11 different saffron (Crocus sativus L.) sources ., Heriberto CaballeroOrtega, Rogelio Pereda-Miranda, Fikrat I. Abdullaev' 